\title{
SISTEMA DE DESCONTAMINAÇÃO DE MÁSCARAS BASEADO NO EFEITO LUMINESCENTE CAUSADO POR ESPECTRO ULTRAVIOLETA (UV-C)
}

\author{
Eder Andrade da Silva \\ GPEnSE/UNILA \\ Paraná, Brasil \\ ea.silva.2020@aluno.unila.edu.br \\ Matheus Vinicius Brandão \\ GPEnSE/UNILA \\ Paraná, Brasil \\ mv.brandao.2016@aluno.unila.edu.br \\ Oswaldo Hideo Ando Junior \\ GPEnSE/UNILA \\ Paraná, Brasil \\ oswaldo.junior@unila.edu.br
}

\author{
Igora Wilis Mauerberg Barbosa \\ GPEnSE/UNILA \\ Paraná, Brasil \\ iwm.barbosa.2018@aluno.unila.edu.br \\ Rafael Andrade Taveira \\ GPEnSE/UNILA \\ Paraná, Brasil \\ ra.taveira.2016@aluno.unila.edu.br
}

\author{
Jose Carlos Navas Palma \\ GPEnSE/UNILA \\ Paraná, Brasil \\ jcn.palma.2016@aluno.unila.edu.br \\ Rafaela Faust Meyer \\ GPEnSE/UNILA \\ Paraná, Brasil \\ rf.meyer.2018@aluno.unila.edu.br
}

\begin{abstract}
With the emergence of the pandemic there was an exponential growth in the consumption of Personal Protective Equipment (EPI) and Collective Protective Equipment (EPC), causing momentary shortages. Hence, in an attempt to protect against the contamination of bacteria and viruses present in the environment, their use became mandatory for health professionals to avoid the contamination and proliferation of COVID-19. Therefore, in order to mitigate and assist the demands, several types of EPI and EPC were developed and donated to the public health care network. In addition, along with the worsening of the pandemic, there was a greater awareness and concern with the well-being and physical integrity of health agents in relation to the risk of contamination associated with labor activities. Consequently, the longer use of EPI, especially masks, as well as of EPCs, was fundamental. In view of the above, this article presents the open source development of an auxiliary disinfection system called mask decontamination system based on the luminescent effect caused by ultraviolet spectrum (UV-C). Considering these assumptions, we developed a system of cleaning masks that consists of a box of sanitization by ultraviolet radiation (UV-C), consisting of an electronic circuit integrated into the structure and with remote control by application. Finally, it is highlighted that $\mathrm{UV}-\mathrm{C}$ radiation is a proven method of disinfection widely used in hospital and laboratory environments in decontamination of surfaces.
\end{abstract}

Keywords: Ultraviolet Radiation; COVID-19; EPI; Sterilization.
Resumo - Com o surgimento da pandemia houve um crescimento exponencial no consumo de Equipamentos de Proteção Individual (EPI) e Equipamentos de Proteção Coletiva (EPC), causando escassez momentânea. Nesse sentido com o intuito de proteger contra a contaminação de bactérias e vírus presentes no ambiente, o seu uso se tornou obrigatório para os profissionais da saúde de modo a evitar a contaminação e proliferação do COVID-19. Portanto, visando mitigar e auxiliar pontualmente as demandas, foram desenvolvidos e doados diversos tipos de EPI e EPC à rede pública de atendimento à saúde. Além disso, junto o agravamento da pandemia, verificou-se uma maior conscientização e preocupação com o bem-estar e integridade física dos agentes de saúde em relação ao risco de contaminação associado às atividades laborais. Consequentemente, fez-se fundamental o uso mais prolongado dos EPIs, em especial as máscaras, bem como de EPCs. Diante do exposto, este artigo apresenta o desenvolvimento open source de um sistema auxiliar de desinfecção denominado sistema de descontaminação de máscaras baseado no efeito luminescente causado por espectro ultravioleta (UV-C). Considerando essas premissas foi desenvolvido um sistema de higienização de máscaras que consiste em uma caixa de higienização por radiação ultravioleta (UV-C), composto por um circuito eletrônico integrado à estrutura e com comando remoto por aplicativo. Finalmente, destaca-se que radiação UV-C é um método de desinfecção consagrado e amplamente utilizado em ambientes hospitalares e laboratoriais na descontaminação de superfícies.

Palavras-chave: Radiação Ultravioleta; COVID-19; EPI; Esterilização. 


\section{INTRODUÇÃO}

A propagação do Covid-19 e a rápida disseminação mundial fez com que as instituições de ensino interrompessem abruptamente suas atividades presenciais em março de 2020 devido ao estado de Pandemia pela disseminação do novo Coronavírus (SARS-CoV-2). No contexto nacional o Brasil tem passado muitas dificuldades para enfrentar a pandemia e flexibilizar a retomada das atividades socioeconômicas, pois estas implicam em garantir a integridade física, criação de protocolos e a publicação de decretos e legislação especifica sobre a rotina, distanciamento social e higienização de objetos, superfícies e espaços para prevenir a propagação do vírus na sociedade [18].

O Brasil encontra-se em declarado estado de calamidade pública, passando a ser gerido através de decretos federais, estaduais e municipais, como por exemplo, a Lei $\mathrm{n}^{\circ}$ 20.189 [1] no estado do Paraná, que define a obrigação do uso de máscaras em lugares fechados, distanciamento entre pessoas entre outros.

No município de Foz do Iguaçu foi publicado o decreto no 28.696, de 6 de novembro de 2020, o qual estabelece de forma condensada que é possível a retomada das aulas presenciais nas instituições de ensino com suas respectivos protocolos e medidas sanitárias, entre estas enfatizando-se na higienização e/ou troca de máscaras a cada duas horas e o persistente ênfases na higienização dos ambientes utilizados na sala de aula [17].

Com a alta demanda por máscaras e equipamentos de segurança (EPIs e EPCs) os estoques se esvaziaram e os custos desses materiais dispararam fazendo com que pesquisas de alternativas fossem feitas e guias [2] e [3] sobre métodos de descontaminação fossem publicados. Estes processos de desinfecção eliminaram a presença de vírus inclusive o SARS-CoV-2 sem danificar a estrutura da máscara N95 ou sua capacidade de filtro. No caso das máscaras reutilizáveis, atualmente são utilizados métodos de descontaminação a base de produtos químicos que podem gerar a deterioração do material com o tempo, ou então é feita a limpeza com água, pode causar o uso excessivo de um recurso natural escasso.

O desenvolvimento de novos aparelhos para descontaminação de ambientes e superfícies vem ao encontro do aumento registrado de contaminados pelo novo Corona vírus a fim de evitar que a contaminação se propague com maior rapidez. Um procedimento que tem mostrado segurança e eficácia na inativação é a radiação ultravioleta [4].

A radiação ultravioleta é a fração do espectro eletromagnético que abrange comprimentos de onda que estão abaixo da luz visível para seres humanos. Esta se subdivide em três tipos, conforme o comprimento de onda, a luz UV-A cobre a faixa entre 320 a $400 \mathrm{~nm}$, a UV-B entre 280 a $320 \mathrm{~nm}$ e a UV-C entre 200 a $280 \mathrm{~nm}$ [5].

A radiação UV-C é a mais danosa, pois tem a capacidade de destruir não só o RNA do vírus como também seu
DNA, por isso é chamada de faixa germinicida [5]. Com isso, é importante que equipamentos que utilizam esta faixa de luz possuam dispositivos de segurança para que não exponha ninguém a luz, evitando danos de saúde aos operantes dos equipamentos.

Com a finalidade de trazer uma opção de descontaminação de máscaras mais econômica e que produza menos lixo, este projeto apresenta o desenvolvimento de um caixa de descontaminação por Luz UV-C para máscaras de uso individual com sistema de acesso remoto para proteção dos usuários.

\section{METODOLOGIA}

A metodologia usada para o desenvolvimento deste projeto envolveu 4 etapas principais, cada qual com subdivisões, conforme apresentado na Fig. 1.

$\mathrm{Na}$ primeira etapa foi feito uma pesquisa bibliográfica contemplando o estado da arte com referências bibliográficas, consulta de produtos e banco de dados de patentes existentes, com o objetivo de ter conhecimento das tecnologias existentes, bem como problemas a se evitar. $\mathrm{Na}$ segunda etapa foi desenvolvido a estrutura da caixa por meio de Modelagem 3D no software Autodesk Inventor®, bem como a impressão desta estrutura por meio de uma impressora 3D (Ender 5 Plus $\left.{ }^{\circledR}\right)$. Paralelamente foi desenvolvido o circuito eletrônico e o aplicativo, bem como a inserção deste circuito na estrutura impressa, formando assim, a terceira etapa. Por fim, na quarta etapa ocorreu a associação do App ao sistema para acesso remoto assim como a avaliação e validação do sistema completo.

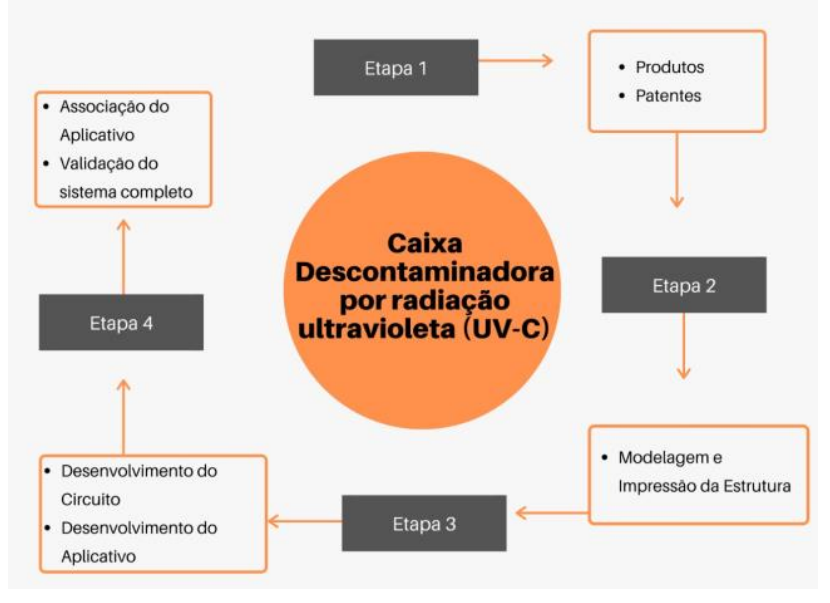

Fig. 1. Fluxograma de metodologia de execução do projeto.

\section{ESTADO DAARTE}

Durante o ano de 2020, as pesquisas relacionadas ao uso da luz ultravioleta foram ampliadas, motivo pelo qual houve muito desenvolvimento científico e registro de várias patentes voltadas para sistemas de esterilização. Isto se deve à grande relevância com que se tem levado a higienização de todas as superfícies e objetos para evitar contaminações por vírus e bactérias. Portanto, serão comenta- 
dos abaixo os desenvolvimentos considerados relevantes para este projeto.

Como forma alternativa às autoclaves, que são ferramentas comumente usadas em laboratórios para esterilização de materiais, a radiação ultravioleta germicida foi determinada uma aliada na descontaminação de vírus nos objetos. Segundo Castro [6], a eficácia desse método foi confirmada com uma série de vírus, incluindo o SarsCoV-1, sendo considerada uma barreira secundária de limpeza de superfícies e ambientes. Desta forma, a UV-C poderá ser implantada como um reforço aos protocolos de desinfecção ambiental, embora a luz não alcance algumas áreas sombreadas.

Ueki [7] comparou placas expostas à luz UV-C, uma envolta em papel alumínio e outra diretamente direcionada à luz. O pesquisador constatou que na placa com exposição direta à luz não houve crescimento de colônias enquanto na placa protegida pelo papel alumínio havia crescimento de colônias. Logo, provou-se no experimento que a exposição de apenas 5 minutos à luz ultravioleta, de forma direta à superfície, já possui o efeito germicida.

Yang [8] comprovou a eficiência da Luz UV-C para o combate de diversas bactérias. $\mathrm{O}$ estudo mostra uma grande redução da presença de bactérias quando submetidas a 5 min de exposição a luz ultravioleta à uma distância de 3 metros. Ao testar em um ambiente hospitalar, houve uma grande redução das bactérias em diferentes superfícies após 15 minutos de exposição a luz.

Segundo Nogee e Tomassoni [9], as fontes de radiação ultravioleta germicida já utilizadas para esterilização de equipamentos de laboratório podem ser calibradas para esterilização de máscaras e protetores faciais. E com as instruções necessárias podem ser implantadas em pequenas instalações ou pontos de atendimento para a utilização. Também destacam a importância de manter as máscaras de uso individual para que o usuário possa acompanhar a confiabilidade do material e saber a quantos ciclos de descontaminação seu equipamento foi submetido.

Para que haja eficiência na descontaminação, Benedetti [10] diz que a dose de radiação ultravioleta UV-C deve superar $1 \mathrm{~J} / \mathrm{cm}^{2}$ por mais de 15 minutos. Segundo o autor, o principal inconveniente em relação a aplicação de radiação UV é a degradação da máscara, mas que conforme uma pesquisa da Universidade de Nebraska, as máscaras se deterioram antes por conta do uso do que pela exposição à radiação.

O Instituto de Física de São Carlos [11] desenvolveu um equipamento para descontaminação de superfícies, chamado Surface UV, o dispositivo pode ser utilizado como uma alternativa na desinfecção de pequenas áreas, instrumentos e superfícies. $\mathrm{O}$ equipamento inativa microrganismos e reduz a disseminação destes, controlando a incidência de infecções nos ambientes. $\mathrm{O}$ produto não pode ser utilizado diretamente na pele humana nem em animais.
Medina registrou a patente $n^{\circ} \operatorname{ES} 1252549$ (U) [12] , aonde desenvolveu "Cajón para guardar dinero en efectivo con sistema de esterilización mediante luz ultravioleta y ventilación forzada" que consiste em uma gaveta que é dividida em compartimentos para colocar notas em pares e/ou moedas usando espaçadores. Estes espaçadores servem como suporte para a fonte de luz ultravioleta. A gaveta também conta com ventiladores nas paredes laterais, para provocar a separação das notas emparelhadas por ventilação forçada quando a fonte de luz ultravioleta estiver em funcionamento conseguindo esterilizar ambos os lados das notas.

A Patente BR 1020190233796 A2 [13] apresenta um “Aparelho descontaminador por luz UV adaptável a linha moveleira" foi criado por George Uriarte Scaranto, desenvolvido para ser embutido, adaptado ou acoplado em armários, gavetas e cômodas já existentes ou compor a estrutura de novos móveis, assim como pode ser usado de sobrepor ou até mesmo com estrutura própria para ficar em pé sem a necessidade de ser embutido. O invento possui como objetivo, a descontaminação por meio de luz ultravioleta de instrumentos e objetos da área hospitalar, consultórios, salões de beleza, clínicas de estética, utensílios domésticos (talheres, acessórios, roupas e demais objetos de higiene pessoal).

A Patente BR 1020190233796 A2 [14] consiste em uma "Caixa esterilizadora à base de luz UV-C com placa de quartzo". A invenção descreve um aparelho esterilizador à base de luz UV-C com placa de Quartzo e espelhos refletores destinado a esterilização de diversos produtos e instrumentos, principalmente instrumentos da área da saúde humana e animal, áreas afins e no uso doméstico. Este equipamento executa a esterilização em ciclos de curta duração, proporcionando economia de tempo, redução do quantitativo de instrumentos ociosos, praticidade no manuseio, dispensando conhecimento especializado, fácil manutenção e baixo consumo de energia.

A Patente CA3095168 A1 [15] consiste em um "Sistema de desinfecção e controle de baixa dosagem" que utiliza dados empíricos e teóricos para comparar o desempenho, dados do sensor, padrões armazenados, uso histórico, índices de intensidade de uso ao longo do tempo e informações de rastreamento para fornecer um sistema sofisticado de coleta de dados para desinfecção.

O produto pode incluir uma camada externa de material transmissor de UV formando uma superfície externa de toque. O sistema de desinfecção por UV inclui uma fonte de UV interna ao produto. Em uso, a fonte UV interna produz luz UV-C que passa e permeia a camada externa para tratar a superfície de toque.

A patente ES 1254591 U [16] consta de um "Cabine de Desinfecção de Roupas" a qual é caracterizada pela configuração prismática que adota, esta configuração consiste em uma única porta de acesso e sobre o teto do mesmo o quadro elétrico e nas suas paredes laterais constam as lâmpadas de luz UVC. Além disso o interior da cabine 
conta com sensores de medição de radiação UVC. Com a finalidade de se comunicar com o sistema de segurança para impedir que o processo de descontaminação ocorra com as portas abertas ou com pessoas dentro desta.

A luz UV-C descontamina apenas a superfície na qual entra em contato [6] por este motivo é necessário que toda superfície da máscara seja atingida pela radiação. Dado este fato foi desenvolvido um sistema de descontaminação que utiliza a radiação ultravioleta germicida (UV-C), consistindo em uma caixa que encapsula o circuito, componentes eletrônicos e a lâmpada de radiação ultravioleta, com a dificuldade de atingir todas as partes da máscara para a descontaminação foi acrescentado ao sistema dois servomotores que mantém a máscara girando enquanto o sistema funciona para garantir a descontaminação total da máscara.

Levando em consideração estas informações, também foi desenvolvido um aplicativo, que será disponibilizado junto à caixa de descontaminação por luz UVC, para que o operador possa escolher o tempo de descontaminação da máscara que se encontra em seu interior de 5 em 5 minutos.

O produto desenvolvido nesse projeto foi um protótipo específico para a desinfecção das máscaras, visando maior durabilidade da máscara, comparado a descontaminação com produtos químicos, economia para os hospitais e postos de saúde, garantindo a segurança aos funcionários.

\section{DESENVOLVIMENTO}

Nesta seção aborda-se o desenvolvimento do sistema de descontaminação de máscaras baseado no efeito luminescente gerado pela radiação ultravioleta (UV-C) que consiste em uma caixa em formato oval com separação em 3 partes, sendo estas a base, a tampa e a capa.

A base possui encaixe para o circuito elétrico que comanda o acionamento de uma lâmpada UV-C e dois servo motores que possuem a finalidade de girar as máscaras quando o sistema estiver ligado para que a radiação atinja todas as superfícies da máscara.

O circuito foi desenvolvido juntamente com um aplicativo para que a comunicação da caixa seja feita de maneira remota. A tampa possui abertura para passagem da lâmpada e das máscaras, visando manter o circuito elétrico protegido. A capa visa fechar todo o sistema para que a radiação ultravioleta não entre em contato com o ambiente externo, protegendo os operantes.

\section{A. Projeto e Desenvolvimento Mecânico e Estrutural}

A estrutura da caixa foi desenvolvida visando a descontaminação das máscaras desenvolvidas pelo grupo, durante o início do projeto e modelos similares. A modelagem foi feita com o intuito de utilizar uma impressora 3D disponibilizada pela universidade para sua elaboração.
O primeiro modelo da caixa foi pensado em formato cúbico e durante o desenvolvimento chegou-se à conclusão de que a caixa em formato oval seria mais indicada, tanto em tempo economizado quanto em economia de material de impressão. Além disso, este formato aproveita mais espaço interno permitindo que as máscaras possam girar dentro da caixa promovendo a descontaminação de toda superfície interna e externa da mesma.

Portanto, a caixa foi desenvolvida em formato oval e dividida em 3 peças principais, a base, aonde seria instalado o circuito eletrônico, a tampa, que serviria para fechar e proteger o circuito, deixando exposto apenas a lâmpada e os suportes para encaixe das máscaras para descontaminação, e então uma capa, para fechar toda a estrutura e garantir a proteção dos operadores em relação à exposição à radiação. Na figura 2 é possível visualizar o sistema por inteiro a forma que as 3 partes se encaixam.
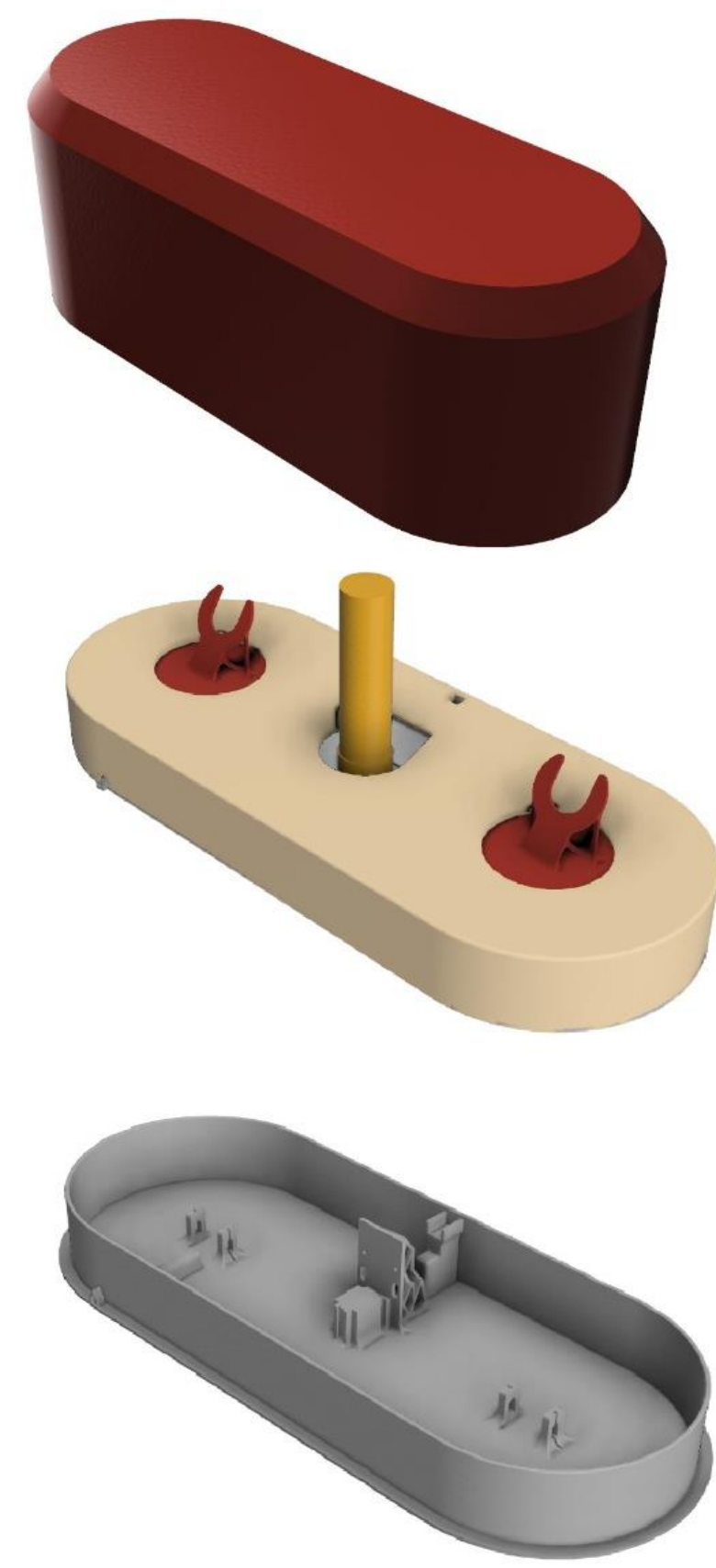


\section{Fig. 2. Demonstrativo da Caixa de Higienização UV-C}

No processo de fabricação das peças, devido a problemas de impressão (falhas mecânicas) foi necessário dividir os modelos em pequenas peças para aproveitar as peças já produzidas sendo que para uma nova fabricação, não se faz necessário essa divisão da peça.

Na Figura 3, apresenta-se o apoio mecânico da máscara, na caixa de higienização, sem ter a necessidade de apresentar sistemas de presilhas.

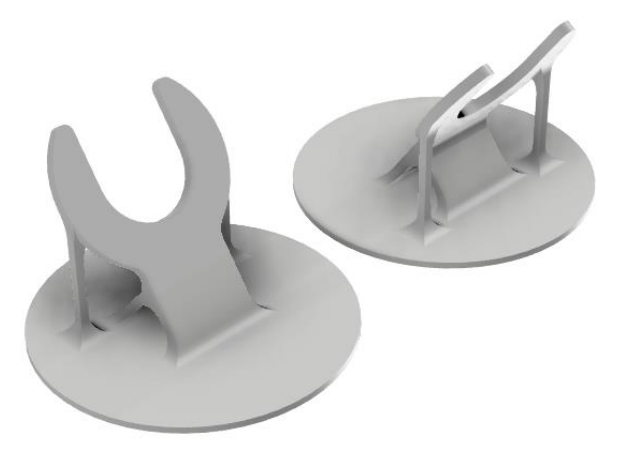

Fig. 3. Apoio de eixo para o EPI produzido.

Para apresentar sustentação ao eixo principal de rotação, foi desenvolvida uma peça suporte para o eixo. De forma circular e de encaixe, essa peça constitui o suporte necessário para não haver problemas adicionais, conforme mostra a Figura 4.
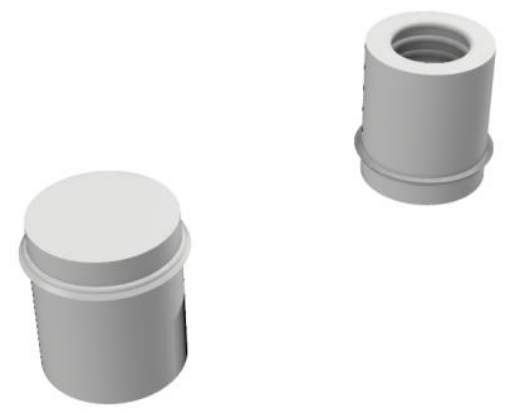

Fig. 4. Demonstrativo do suporte do eixo.

Logo, se vez necessário o desenvolvimento de uma peça para posicionar o rolamento, que permitisse a rotação do EPI para a descontaminação cobrir toda a região necessária do EPI. Sendo assim, uma peça fundamental para a eficácia do sistema, conforme a Figura 5.
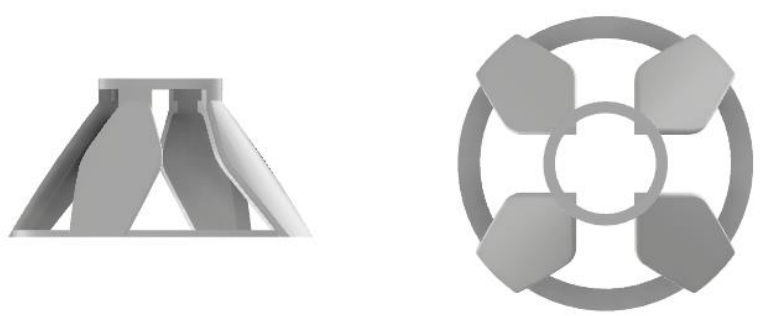

Fig. 5. Suporte do EPI com o acoplamento do eixo

Por fim, para completar o sistema e fechá-lo, foi desenvolvida uma tampa, no mesmo formato que a base, para fechar o sistema e, assim, completar todo o protótipo e sistema de descontaminação por luz UV-C. A tampa pode ser observada na Figura 2 já apresentada.

Com todas essas peças combinadas, o sistema apresenta, externamente, o protótipo com e sem capa apresentado nas Figuras 6 e 7, respectivamente. Sendo produzida, cada componente, por impressão 3D e viabilizando a otimização de material e tempo.

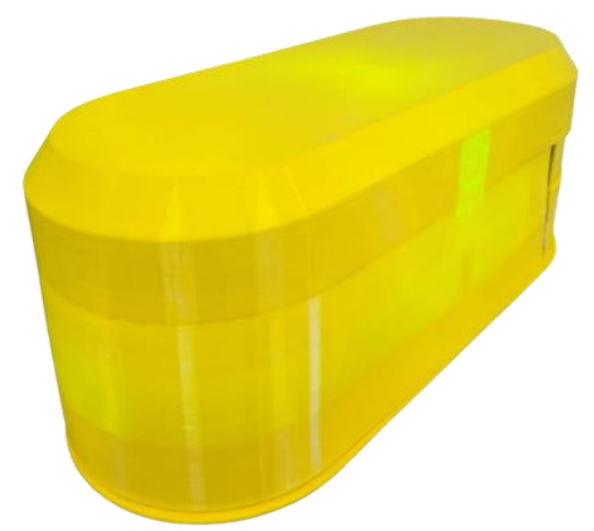

Fig. 6. Sistema completo da caixa de descontaminação UV-C.

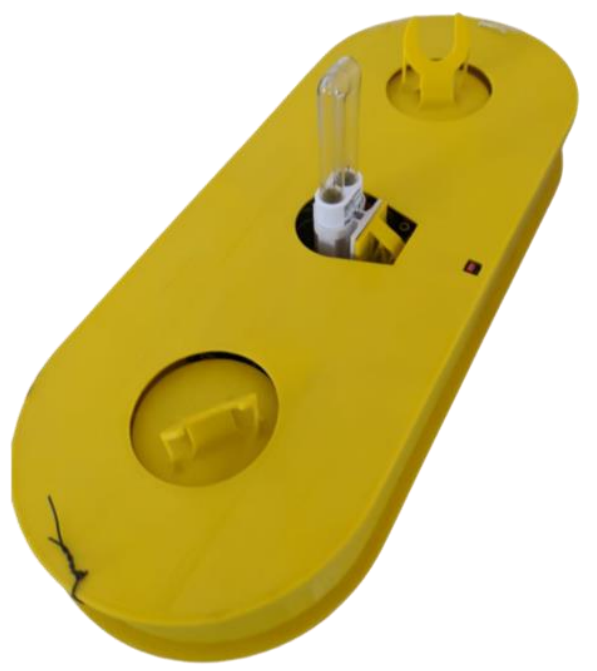

Fig. 7. Sistema completo da caixa de descontaminação UV-C sem capa.

\section{B. Desenvolvimento do Circuito Eletrônico}

Este capítulo apresenta o circuito eletrônico desenvolvido dividido em fonte de alimentação, circuito de processamento e controle, assim como o circuito de comunicação e a descrição de funcionamento de cada um. Nas Figuras 8 e 9, apresenta-se o circuito esquemático utilizado. 


\section{LATINOWARE 2020}

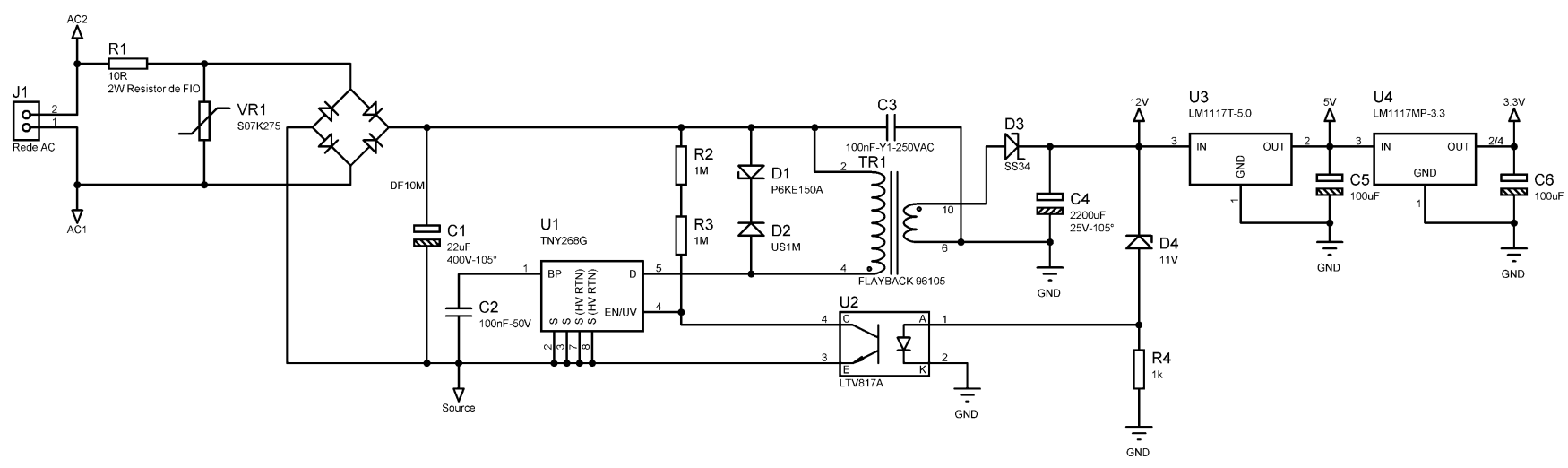

Fig. 8. Circuito da fonte de alimentação

A fonte de alimentação é responsável por gerar os valores de tensão fixos necessários para o correto funcionamento dos dispositivos eletrônicos. A mesma foi projetada para operar com tensão de entrada de 90 a 240VAC e fornece os valores fixos de 12,5 e 3,3Vcc. Desenvolvida com o circuito integrado da família TinnySwitch produzido pela Power Integrations opera na topologia Flyback garantindo o isolamento do secundário que realiza a leitura do feedback por meio de um foto-acoplador.

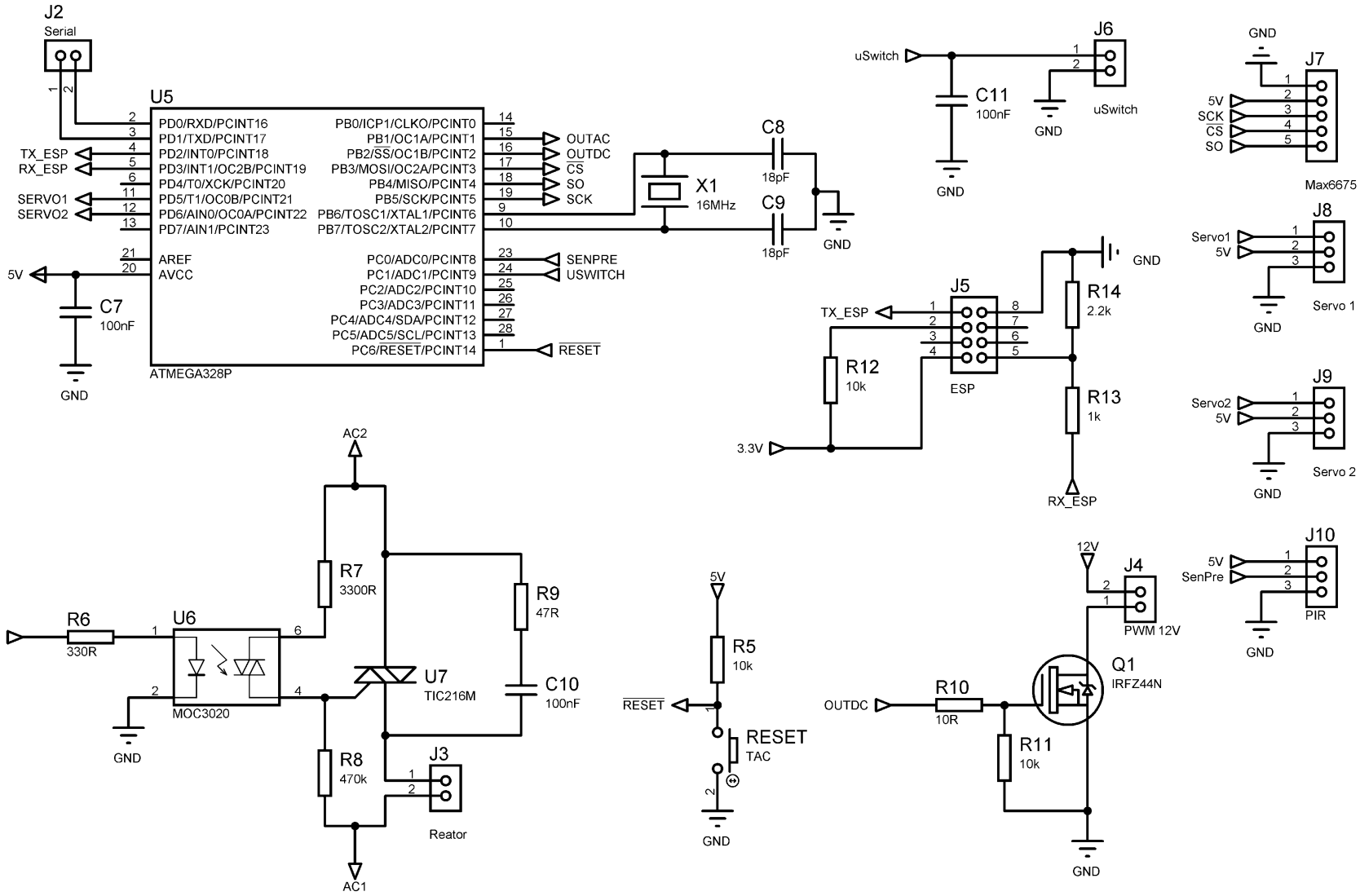

Fig. 9. Circuito de processamento e controle

O circuito de processamento e controle possui como microcontrolador o Atmega328p, mesmo microcontrolador de um Arduino UNO. Esse sistema é responsável por monitorar as condições de funcionamento do sistema além de atuar como mediador entre o App, que será descrito em seguida, e o sistema de higienização. Pensando em atender as necessidades de segurança e controle das cargas, foram definidas as conexões de entradas e saídas. Como entrada a microswitch provê segurança mecânica ao sistema, tendo em vista que é acionada quando a tampa da caixa é aberta estando a lâmpada UV-C acesa. Quando o microcontrolador recebe o sinal proveniente do microswitch, esse, imediatamente, desliga a lâmpada UV-C e evita que o operador tenha contato com a luz ultravioleta.

Previou-se também uma entrada para um sensor com saída analógica de 0 a $5 \mathrm{~V}$ que pode ser implementado para verificação de presença ou medidor de temperatura ambiente, assim como um borne de conexão para o MAX6675 que é um drive para termopar tipo K, o qual realiza o mo- 
nitoramento de temperatura das lâmpadas UV-C. O controle de temperatura é necessário e garante a segurança contra sobre temperaturas ocasionadas pela operação contínua da lâmpada UV-C.

Foram previstos dois bornes (J8 e J9) de conexão para os dois servo motores SG90 que tem o papel de girar as máscaras de modo que toda a superfície das mesmas possa ser tocada pela luz UV emitida pela lâmpada, assim como uma interface de acionamento de carga em corrente continua de $12 \mathrm{~V}$ através de um mosfet IRFZ44N e a de acionamento em corrente alternada através de um triac

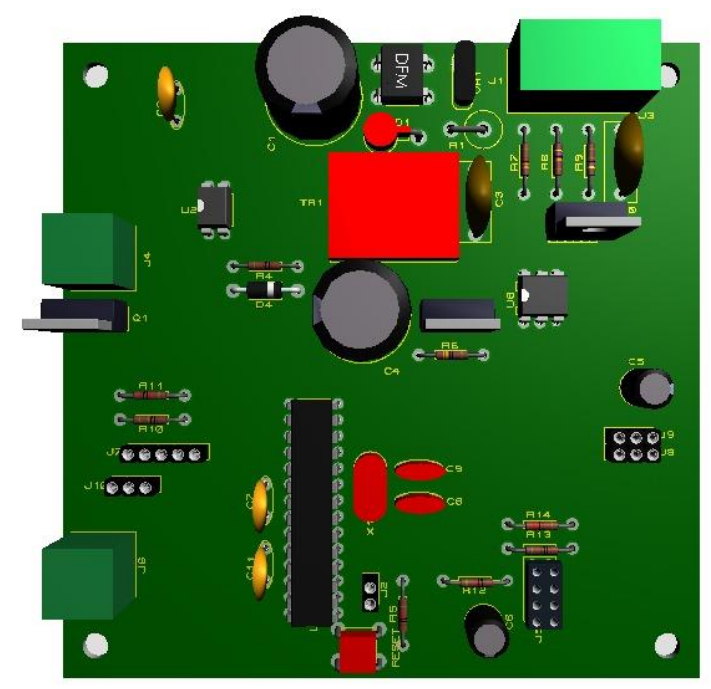

(a)
TIC216 que realiza o acionamento do reator das lâmpadas UVC.

O circuito de comunicação com a internet utilizado é o controlador de internet sem fio ESP01, que se comunica com o ATmega328p através do borne J5, a interface entre o ESP e o ATmega é composta por um divisor resistivo com a finalidade de compatibilizar a comunicação realizada entre os 5V utilizados no ATmega e os 3,3V do ESP01. O circuito foi simulado no software Proteus antes de sua montagem e está apresentado na Figura 10.a, bem como o circuito desenvolvido e soldado na placa pode ser visto na Figura 10.b.

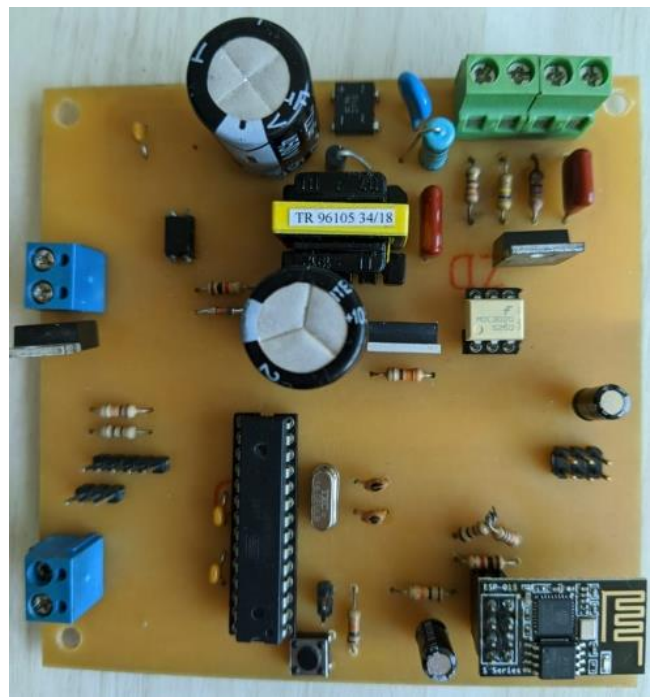

(b)

Fig. 10. Demonstrativo do (a) circuito eletrônico simulado no Proteus e do (b) circuito eletrônico desenvolvido.

Caso os parâmetros de funcionamento do sistema estejam dentro dos padrões, o sistema passa a receber os comandos provenientes do usuário através do App. Esses comandos envolvem valores relacionados às preferências de higienização das máscaras.

A lâmpada UV tem o papel de emitir ondas em frequência específica para higienização de superfícies e necessita do reator para que a tensão nela alcance valores altos necessários para o funcionamento desse componente.

\section{Desenvolvimento do Aplicativo}

O sistema é provido de um aplicativo que permite ao usuário controlar remotamente o equipamento através de uma conexão WiFi simples.
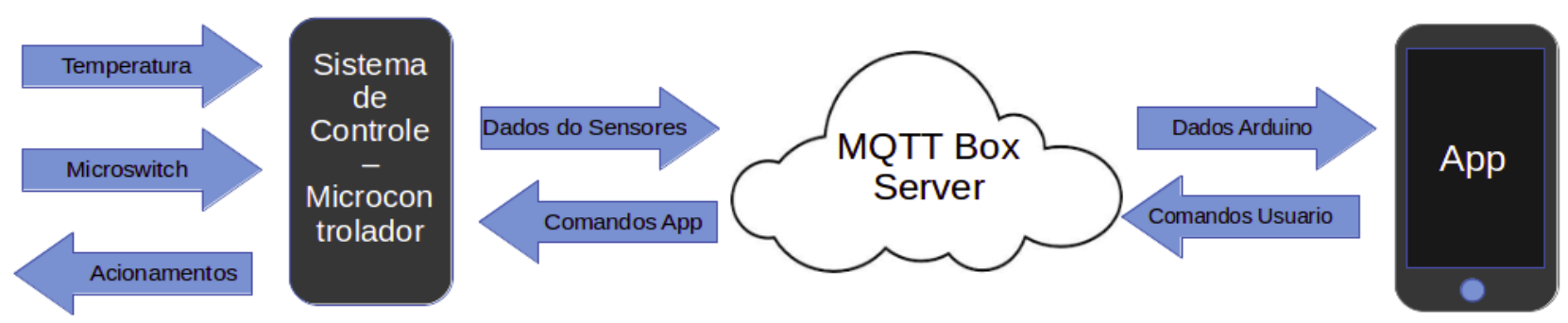

Fig. 11. Esquemático do sistema de controle do aplicativo.
A aplicação envia e recebe dados ao sistema de controle através de um protocolo web chamado Message Queuing Telemetry Transport (MQTT). Isso permite que o usuário controle o funcionamento do aparelho em qualquer parte do mundo, desde que tenha uma conexão WiFi.

Para o design e programação do aplicativo foi utilizado o programa App Inventor $\AA$ bem como linguagem Java e C++ para adaptação de bibliotecas. De maneira geral, o esquema da Figura 11 mostra o funcionamento do sistema de controle e do App. Quando o usuário insere valores no App, estes são enviados ao sistema de controle através do MQTT e o sistema opera conforme as condições escolhidas. 
Na Figura 12 encontra-se o demonstrativo das telas acessadas pelo usuário no aplicativo desenvolvido. $\mathrm{O}$ aplicativo possui 4 telas, a tela de acesso (a), aonde o usuário poderá selecionar qual sistema ele deseja configurar e então será direcionado para a tela de controle (b) deste sistema, aonde poderá preencher os seguintes parâmetros: (i) Tempo de Higienização: Tempo em que o sistema de higienização permanecerá ligado; (ii) Intervalo: Tempo entre cada período de higienização em que o sistema de potência está desligado e (iii) Ciclos de Higienização: Quantas vezes o sistema repetirá o ciclo HigienizaçãoIntervalo.

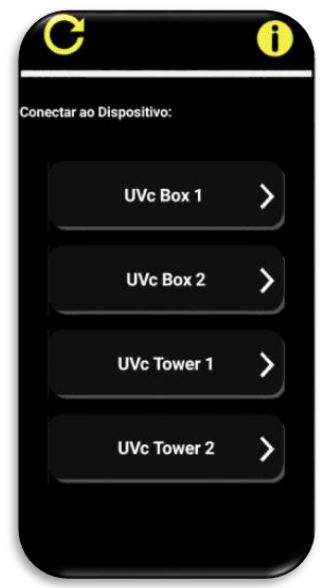

(a)

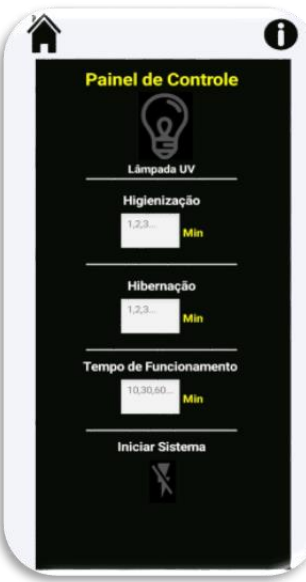

(b)

Depois de selecionar os parâmetros, o usuário é direcionado para a tela de funcionamento (c) do sistema que possui o tempo restante de funcionamento do sistema e status, mostrando pelo ícone da lâmpada, se o ciclo está na etapa de higienização (com a lâmpada ligada) ou no tempo de intervalo (lâmpada desligada). Além disso, há uma tela (d) disponível para ser acessada a qualquer momento pelo ícone do (i), nesta tela constam as informações dos responsáveis pelo desenvolvimento do aplicativo e contato, para caso o usuário esteja tendo problemas, solicitar ajuda.

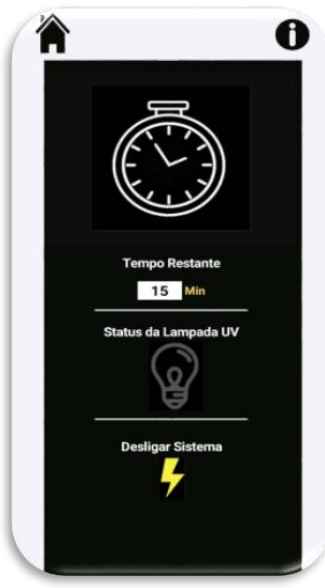

(c)

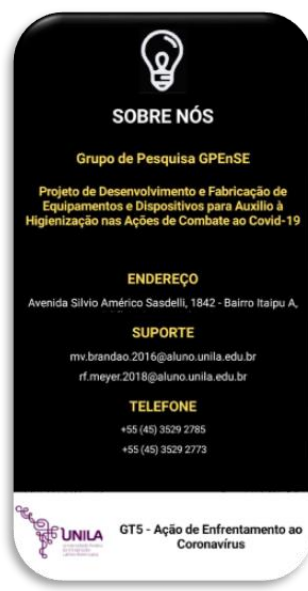

(d)

Fig. 12. Esquemático do sistema de controle do aplicativo.

\section{RESULTADOS E PROCESSOS AVALIATIVOS}

O sistema desenvolvido trata-se de uma caixa de descontaminação por luz ultravioleta (UV-C) capaz de desinfectar máscaras contra o novo Corona vírus e outras bactérias para que seja possível a reutilização destas. Apesar de ter sido elaborado para descontaminação de máscaras, os pedestais podem ser retirados e outras superfícies podem ser higienizadas utilizando o mesmo sistema, desde que a luz atinja o objeto por completo.

A avaliação do protótipo foi realizada de forma funcional, verificando seu acesso remoto e controle pelo aplicativo bem como o funcionamento do sistema completo. Durante a realização do teste o sistema acionou de forma prevista, ligando a lâmpada e acionando os servos motores conforme o programado no aplicativo.

\section{CONCLUSÃO}

A presente proposta atende as especificações iniciais por ser uma solução funcional, de fácil prototipação e acessível, principalmente, quando comparada ao custo de sistema comercial.

A Caixa Higienizadora por UV-C visa auxiliar na higienização das máscaras utilizadas pelos profissionais da saúde. Tendo como motivador ajudar no enfrentamento ao novo Coronavírus (SARS-CoV-2) oferecendo mais segu- rança às pessoas que precisam trabalhar em ambientes fechados e expostos a vírus e bactérias.

Destaca-se que o protótipo apresentou resultados satisfatórios quanto a sua funcionalidade e aplicação proposta. Porém, devido ao agravamento da pandemia e priorização no atendimento a demandas da sociedade local não foi possível realizar teste e validação microbiológica do dispositivo em operação.

Cabe destacar a importância da participação da comunidade na execução da atividade de extensão; o impacto e a transformação social proporcionada pela atividade de extensão e a contribuição da atividade de extensão na formação acadêmica dos estudantes envolvidos.

Por fim, o sistema de descontaminação que utiliza a radiação ultravioleta germicida (UV-C) trata-se de uma ferramenta alterantiva de auxilio à proliferação de vírus e bacteriais em ambientes hospitalares e laboratóriais. Diante disso, visando auxiliar e contribuir no enfrentamento da Pandemia, os autores estão disponibilizando gratuitamente e na integra todos os documentos e materiais necessários para replicar e construir o dispositivo. Os conteúdos encontram-se disponível para download na página da Universidade Federal da Integração Latino-Americana (UNILA) pelo link: https://portal.unila.edu.br/doutorado/ppgies/produto- 
$\underline{\text { tecnologico. }}$

\section{AGRADECIMENTOS}

Os autores agradecem à Universidade Federal Integração Latino-Americana (UNILA), Programa de PósGraduação em Energia e Sustentabilidade (PPGIES), ao Programa Agenda Tríplice da UNILA e ao Grupo de Pesquisa em Energia e Sustentabilidade Energética (GPEnSE) por disponibilizar a infraestrutura e fomento para esta pesquisa. Agradecemos também ao Conselho Nacional de Desenvolvimento Científico e Tecnológico (CNPq) e Fundação Araucária (FAPPR).

\section{REFERÊNCIAS}

[1] CASA CIVIL DO GOVERNO DO ESTADO DO PARANÁ. Lei n ${ }^{\circ}$ 20189, de 20 de abril de 2020. -. [S. 1.], 28 abr. 2020. Disponível em:

https://www.legislacao.pr.gov.br/legislacao/listarAtosAno.do?actio $\mathrm{n}=$ exibir\&codAto $=234115 \&$ indice $=1 \&$ totalRegistros $=64 \&$ anoSpan $=2020 \&$ anoSelecionado $=2020 \&$ mesSelecionado $=0 \&$ isPaginado $=\operatorname{tr}$ ue. Acesso em: 4 nov. 2020

[2] MINISTÉRIO DA SAÚDE (Brasil). Enfrentamento ao Coronavírus. Sobre a Doença. Ministério da Saúde, [s. 1.], 6 abr. 2020. Disponível em: https://coronavirus.saude.gov.br/sobre-adoenca\#tinterna. Acesso em: 4 nov. 2020.

[3] AGÊNCIA NACIONAL DE VIGILÂNCIA SANITÁRIA ANVISA. Guia, 2012. Segurança do paciente em serviços de saúde: limpeza e desinfecção de superfícies, Brasília, 1 jan. 2012. Disponível em: https://www20.anvisa.gov.br/segurancadopaciente/index.php/publi cacoes/item/seguranca-do-paciente-em-servicos-de-saude-limpezae-desinfeccao-de-superficies. Acesso em: 6 nov. 2020.

[4] DEFESANET (Brasília). Cobertura Especial. Descontaminação de ambientes e superfícies com Luz Ultravioleta: Medida Eficaz de Combate ao COVID-19. In: DEFESANET (Brasília). Cobertura Especial. Descontaminação de ambientes e superfícies com Luz Ultravioleta: Medida Eficaz de Combate ao COVID-19. [S. 1.], 31 mar. 2020. Disponível em: https://www.defesanet.com.br/pw/noticia/36281/. Acesso em: 4 nov. 2020.

[5] HALLIDAY, David; RESNICK , Robert; WALKER, Jearl. ONDAS. In: HALLIDAY, David; RESNICK , Robert; WALKER, Jearl. Fundamentos de Física - vol.2 (Gravitação, Ondas e Termodinâmica). 9. ed. [S. 1.]: LTC, 2011. v. 2, cap. 16,17, p. 115181.

[6] CASTRO, Carla Cecília Lira Pereira et al. ADAPTAÇÃo DOS CIRURGIÕES-DENTISTAS FRENTE À AMEAÇA DA COVID19. Brazilian Journal of Development, [s. 1.], 2 set. 2020. DOI https://doi.org/10.34117/bjdv6n9-035. Disponível em: https://www.brazilianjournals.com/index.php/BRJD/article/view/16 029. Acesso em: 4 nov. 2020.

[7] UEKI, Suely Yoko Mizuka et al. Monitoramento em cabine de segurança biológica: manipulação de cepas e descontaminação em um laboratório de micobactérias: Biological safety cabinet monitoring: strains manipulation and decontamination in a mycobacteria laboratory. Jornal Brasileiro de Patologia e Medicina Laboratorial, [s. 1.], 1 ago. 2008. Disponível em:
https://www.scielo.br/scielo.php?pid=S1676-

24442008000400005\&script=sci_arttext. Acesso em: 4 nov. 2020.

[8] YANG, Jui-Hsuan et al. Effectiveness of an ultraviolet-C disinfection system for reduction of healthcare-associated pathogens. ScienceDirect, [s. 1.], 18 set. 2017.

[9] NOGEE, Daniel; TOMASSONI, Anthony J. Concise Communication: Covid-19 and the N95 Respirator Shortage: Closing the Gap. The Society for Healthcare Epidemiology of America, [s. 1.], 28 mar. 2020. Disponível em: https://www.researchgate.net/publication/340608895_Concise_Co mmunication_Covid-

19_and_the_N95_Respirator_Shortage_Closing_the_Gap. Acesso em: 4 nov. 2020.

[10] BENEDETTI, Rubén. ¿Descontaminar y reutilizar un EPP descartable? Las mascarillas N95 en tiempos de pandemia. UNR, [s. 1.], 1 jul. 2020. Disponível em: http://rephip.unr.edu.ar/bitstream/handle/2133/18085/Esterilizar\%2 0y\%20reutilizar\%20un\%20EPP\%20descartable-

1.pdf?sequence=3\&isAllowed=y. Acesso em: 4 nov. 2020 .

[11] SINTRA, Rui. Equipamentos desenvolvidos no IFSC/USP descontaminam superfícies. In: COVID-19. [S. 1.], 24 mar. 2020. Disponível em: https://www2.ifsc.usp.br/portal-ifsc/equipamentosdesenvolvidos-no-ifsc-usp-descontaminam-superficies/. Acesso em: 4 nov. 2020.

[12] ALEJANDRO, Jose Medina. Cajón para guardar dinero en efectivo con sistema de esterilización mediante luz ultravioleta y ventilación forzada. Depositante: Jose Medina Alejandro.. Titular: Jose Medina Alejandro. ES1252549 (U). Depósito: 11 set. 2020. Concessão: 11 set. 2020.2 Disponível https://lp.espacenet.com/publicationDetails/biblio?II $=7 \& \mathrm{ND}=3 \& \mathrm{ad}$ jacent $=$ true $\&$ locale $=$ es_LP $\& F T=D \&$ date $=20200911 \& C C=E S \& N R$ $=1252549 \mathrm{U} \& \mathrm{KC}=\mathrm{U}$. Acesso em: 4 nov. 2020 .

[13] SCARANTO, George Uriarte. Aparelho descontaminador por luz UV adaptável a linha moveleira. Depositante: George Uriarte Scaranto. Titular: George Uriarte Scaranto. BR 1020200078275 A2. Depósito: 20 abr. 2020. Concessão: 25 ago. 2020. Disponível em:

https://gru.inpi.gov.br/pePI/servlet/PatenteServletController?Action $=$ detail $\&$ CodPedido $=1574744 \&$ SearchParameter $=$ UV $\% 20 \% 20 \% 20$ $\% 20 \% 20 \% 20 \&$ Resumo $=\&$ Titulo $=$. Acesso em: 4 nov. 2020 .

[14] SELLLA, Antonio Valentim. Caixa Esterilizadora à base de Luz UV-C com placa de Quartzo. Depositante: Plazadente Industira de Produtos de Toucador - EIRELI. Titular: Antonio Valentim Sella. BR 1020190233796 A2. Depósito: 7 nov. 2019. Concessão: 18 fev. 2020. Disponível em: https://gru.inpi.gov.br/pePI/servlet/PatenteServletController?Action $=$ detail $\&$ CodPedido $=1527648 \&$ SearchParameter $=$ UV $\% 20 \% 20 \% 20$ $\% 20 \% 20 \% 20 \&$ Resumo=\&Titulo=. Acesso em: 4 nov. 2020 .

[15] BAARMAN, David W. Disinfection Behavior Tracking and Ranking. Depositante: UV PARTNERS INC.. Titular: David W Baarman. CA3095168 (A1). Depósito: 25 mar. 2019. Concessão: 3 out. 2019. Disponível em: https://pt.espacenet.com/publicationDetails/biblio?II=1\&ND=3\&ad jacent $=$ true $\&$ locale $=$ pt $\_P T \& F T=D \&$ date $=20191003 \& C C=C A \& N$ $\mathrm{R}=3095168 \mathrm{~A} 1 \& \mathrm{KC}=\mathrm{A} 1$. Acesso em: 4 nov. 2020.

[16] GTG INGENIEROS, S.L. Cabina de Desinfección de Ropas. Depositante: GTG INGENIEROS, S.L. ES 1254591 U. Depósito: 1 
jul. 2020. Concessão: 27 jul. 2020. Disponível em: https://bopiweb.com/cabina-de-desinfeccion-de-ropa/3562638/.

Acesso em: 4 nov. 2020.

[17] FOZ DO IGUAÇU. Decreto n 28.682, de 6 de novembro de 2020. Institui o Protocolo Sanitário, Administrativo e Pedagógico. [S. 1.], 6 nov. 2020.

[18] WERNECK, Guilherme Loureiro et al. La pandemia de COVID-19 en Brasil: crónica de una crisis sanitaria anunciada. REPORTS IN PUBLIC HEALTH, [S. 1.], p. 1-4, 8 jul. 2020. DOI 10.1590/0102-
311 X00068820.
Disponível

em:

https://www.scielo.br/pdf/csp/v36n5/es_1678-4464-csp-36-05-

e00068820.pdf. Acesso em: 11 nov. 2020. 